\title{
The Impact of a Brief Home-Based Intervention on Families with a Child with Autism Spectrum Disorder
}

\author{
Audrey Mullan ${ }^{1} \cdot$ Kerry Boyd $^{1} \cdot$ Roy McConkey ${ }^{2}$ (D) \\ Accepted: 7 September 2020 /Published online: 18 September 2020 \\ (C) The Author(s) 2020
}

\begin{abstract}
A brief intervention is described and evaluated that aimed to build and strengthen relationships for families of children diagnosed with ASD aged 12 and under. A particular focus was on socially disadvantaged parents. Parents were offered around five home visits which took place on weekdays during working hours; each lasting around $90 \mathrm{~min}$. They were given individualised practical tools and support to manage their children's behaviours alongside providing a listening ear to parents' concerns. In all, 456 children and 427 families participated over a four-year period with a take-up rate of $87 \%$ of all referrals. The drop-out rate was low $(4.5 \%)$ as was the proportion of missed and cancelled appointments. Parents' satisfaction ratings were high and most found the number of sessions provided was 'just right'. Children improved in their personal care, had less difficulty with change, showed less anger and had fewer meltdowns. Parents reported being less stressed, not feeling so down and managing their child better. The evaluations suggested that a brief home-based intervention is a viable and effective means of providing personalized, postdiagnostic support to parents at periodic intervals, although socially disadvantaged families may require additional assistance beyond managing their child's ASD. The project also highlighted broader issues that impede effective support for families.
\end{abstract}

Keywords Children · Autism · ASD · Families · Brief intervention · Service evaluation

Roy McConkey

r.mcconkey@ulster.ac.uk

1 AutismNI, Belfast, UK

2 Institute of Nursing and Health Research, Ulster University, Newtownabbey BT37 0QB, UK 
The global rise in the prevalence rates of children diagnosed with an Autism Spectrum Disorder (ASD) is well established up to 2010 (Elsabbagh et al. 2012). However during the past decade, the rise continued: at least in more affluent countries such as the United States (Kogan et al. 2018) and the United Kingdom (McConkey 2020a).

The increase was particularly marked in Northern Ireland. In the school census taken annually in the UK, 4454 pupils in Northern Ireland were identified in the school year 2010/11 as having ASD: a prevalence rate of 1.41 per 100. By 2018/19, the numbers had risen to 10,627 pupils; an increase of nearly $140 \%$ resulting in a prevalence rate of 3.21 per 100 (McConkey 2020a). A similar increase was apparent in the number of children in Northern Ireland referred to health services for assessment with a rise of $147 \%$ in the number of children diagnosed with ASD over the years from 2015 to 2019 (Department of Health 2018). Not surprising, existing service provision was illequipped to cope with the increased demand.

Early intervention to ameliorate the main symptoms of ASD as soon as the condition is identified, or even suspected, is an agreed priority internationally especially in early childhood (Vivanti et al. 2018). Even so, a national UK survey of over 1000 parents found that only one in five parents received a direct offer of help/assistance (during or following) the diagnostic process. Over $60 \%$ of parents expressed dissatisfaction with post-diagnostic support and only 5\% were very satisfied with it (Crane et al. 2016).

The increased stress experienced by families with a child who has ASD is well recognised (Bonis 2016) as is the poorer quality of life which families experience (Vasilopoulou and Nisbet 2016). To date, the major focus of intervention has been on specialised treatments for the child, such as ABA or visual communication (Landa 2018). Moreover, most interventions for ASD are evaluated only in terms of child outcomes. Rather as Karst and Van Hecke (2012) noted: "It cannot be assumed that even significant improvements in the diagnosed child will ameliorate the parent and family distress already present, especially as the time and expense of intervention can add further family disruption" (p.247). Rather the authors emphasise the importance of addressing family needs as well as those of the child.

The rise in the number of children affected by ASD comes at a time when health and social care budgets are severely curtailed in many countries and access to trained personnel has to be rationed (Hood et al. 2019). As a consequence, increased attention has been paid to the potential that family-mediated interventions can make with children experiencing developmental difficulties (Althoff et al. 2019). Particularly relevant are low cost, relatively brief interventions that would enable all families to receive at least a modicum of support and signpost them to further services for continuing or future support.

For example, McConkey et al. (2011) evaluated the impact of four home visits that were based around a specially developed resource kit for newly diagnosed children with ASD. The sample of 29 mothers reported feeling less stressed in their interactions with their child and improvements in the children's play, imitation and interaction with others. A study in Australia of Stepping Stones Triple P, a brief individualized parenting program adapted for ASD, reported significant effects with 64 parents on their parenting confidence, and parental stress, parental conflict, and relationship happiness (Tellegen and Sanders 2014). Likewise Zand et al. (2018) piloted a four- 
session, manualized, positive parenting program on 21 parents of newly diagnosed children aged 2 through 12 years and reported clinically and statistically significant reductions in child maladaptive behaviors, as well as improvements in parental and family functioning. In India, Manohar et al. (2019) reported that 26 parents who received five, out-patient sessions focusing on social and adaptive skills reported more improvements in parental stress and child outcome measures compared to 24 parents in a control group.

To date, most of these brief, parent-based interventions have been undertaken with small self-selected samples rather than making these interventions available to a wider population and greater number of parents of children diagnosed with ASD. Moreover, limited attention has been paid as to how 'under-resourced' families (those with low incomes and limited education) can be better supported when a child has ASD as often parents in past studies have come from 'well educated, upper middle-class families' (Carr and Lord 2016).

Families from disadvantaged backgrounds face various challenges to participating in intervention programs which is reflected in their lower uptake and higher drop-out rates (Haine-Schlagel and Walsh 2015). Yet a systematic review of home visiting programs concluded that visits by paraprofessionals was a promising intervention for socially high risk families with young children (Peacock et al. 2013). Kasari et al. (2014) contrasted relatively brief home-based and group-based interventions (each $24 \mathrm{~h}$ in all) with low resourced care-givers of children with autism and reported improvements in their core autism deficits but these were more pronounced with families who received home-based intervention: the group that also had fewer drop-outs.

It was against this background that the Reaching Autism Families Together (RAFT) was conceived by AutismNI: the major voluntary organization for autism in Northern Ireland. They partnered with one of the five Health and Social Care (HSC) Trusts which undertake the assessment and diagnosis of children with ASD. The trusts operate under the National Health Service provided by the UK Government to all its citizens free of charge. They have a statutory duty to undertake assessments of 'children in need' and provide suitable treatments and therapies as required. AutismNI made a successful application for five years of funding to the UK National Lottery Community Fund whose monies are given to community groups to fund health, education and environment projects.

This paper has two main aims. First, a description is given of the brief, personalized home-based interventions devised by the project to meet the current needs of children and families. Second, an account is given of the methods used to evaluate the impact of the project and the results obtained.

\section{Description of the Project}

The overall aim of the RAFT project was to build and strengthen relationships for families of children diagnosed with ASD aged 12 and under. In particular, the main objectives were

- To equip families with the knowledge and skills to address the difficulties their child was currently experiencing; 
- To enable the children and families to experience a better quality of home life;

- To reduce the social isolation children and families experience and promote increased levels of community connectedness.

In addition, the project aimed to boost the recruitment of families from disadvantaged circumstances. To that end, the project was located in two districts of the HSC trust which had higher levels of social deprivation. When the project was fully operational, around 100 families could take part each year.

\section{Project Activities}

Three project officers were employed on part-time contracts all of whom were female, held a professional qualification along with postgraduate training in ASD and upwards of two years experience with children who had ASD and their families. A part-time project manager with additional qualifications and 10 years experience of autism interventions and family support was also appointed along with an administrative assistant. Each officer worked in a designated geographical area but the team provided mutual support and guidance to one another and shared relevant resources.

Families were referred mostly from the ASD Children's Team of the HSC Trust which consisted of a community paediatrician, clinical psychologist and occupational therapist with other therapy and social work staff as needed. After diagnosis by the team, families were given the choice of a referral to the RAFT Project. In some instances, families were also referred and seen by the project while waiting for an assessment for ASD. In addition, families could be referred directly to the project by other community organisations, although this rarely happened.

Once a referral was received, an initial meeting was arranged with parents at home to assess the family and child needs using specially developed tools (see below) and the suitability of the project in meeting those needs. Parents were then offered around five home visits which took place on weekdays during working hours. Each meeting lasted between one and two hours. Although five was the intended number of home visits, this could reduce or increase according to parent's needs and wishes as well as the project officer's assessment of progress.

The meetings provided parents with practical tools and support to manage the specific concerns parents had about their child which generally related to the child's behaviours, play activities and socialisation within the family and with other children. Priority goals were identified and broken down into smaller steps as needed in line with SMART principles (Specific, Measurable, Achievable, Realistic, and Timebound).

The main strategies promoted by the project included the use of visual structures to help children's understanding of the tasks they were required to complete; structuring the home environment, setting up and maintaining positive routines, promoting independence in daily living skills and in play and leisure activities, and encouraging organisational skills, through the use of schedules. However these were selected and adapted according to the child and family needs. Visual aids and teaching resources were made by project staff and given to families. Advice and guidance was also offered to parents about any personal issues they raised including managing the child's behaviours, sibling relationships, school work and future school placements. 
Parents were also offered a place on various information sessions and training courses on ASD provided by AutismNI. These took place in local venues, such as community centres and libraries. Also parents were signposted to local ASD parent support groups affiliated to AutismNI and information was provided about other sources of community support that could assist families in their locality.

At the end of the home visits, parents were informed of the AutismNI's helpline phone number for further advice or support. A follow-up phone call was made up around 12 weeks later to check on how things were going and to provide any further advice that families might require.

\section{Evaluation of the Project}

\section{Methods and Materials}

During the first year of the project, the operational procedures were developed and tested with around 50 families. This included the design of bespoke questionnaires that would assist project officers to identify the needs of the children and parents. The questionnaires would also serve as a means to monitor and evaluate the impact of the project while bearing in mind the need to minimise the extra burden and time placed on parents and on the project staff.

First, demographic information on the children and families was collected. Second, parents rated their child's autism symptoms using one of two screening tools depending on the child's age as an indication of the severity of their child's ASD. For children aged under 4 years, the Q-CHAT 10 was used and for those aged 4 and above the AQ10 (Allison et al. 2012). Third, a questionnaire was specially developed for use by project staff in which parents rated their child's difficulties based on those most commonly reported by parents referred in the first year (see Table 1). This questionnaire was completed again on the final home visit.

Fourth a similar bespoke questionnaire was developed that captured changes in parental wellbeing based on past studies and the objectives of the project. This was tested and adapted in the first year of the project (see Table 2). Parents rated themselves at the start and at the end of the project. A factor analysis of the eight wellbeing items accounted for $48 \%$ of the variance for ratings made at the start of the project (with factor loadings ranging from 0.828 to 0.583 ) and $53 \%$ of the variance for ratings at the end of the project (with factor loadings ranging from 0.842 to 0.612 ). The Cronbach alpha for ratings on the eight items at the start was 0.828 and 0.856 at the end. The testretest correlation between scores before and after was $r=0.806$ (see McConkey 2020b for further details).

In addition, parents completed an evaluation form about their reactions to the project at the end of the home visits. The project workers also reported on the activities they had undertaken with the family and their perceptions of parents' reactions.

\section{Project Uptake and Participation Rates}

Children were mostly referred to the project by the Children's ASD team in the HSC Trust. The team offered families living in the targeted areas, a choice of post-diagnostic 
Table 1 The percentage of families rating changes in their child's behaviours $(N=456)$

\begin{tabular}{llll}
\hline Problem & Never was a problem & $\begin{array}{l}\text { Was a problem- getting } \\
\text { better since project }\end{array}$ & Still a problem \\
\hline Personal care (toileting, dressing) & $13.5 \%$ & $65.8 \%$ & $20.7 \%$ \\
Problem with following instructions & $3.1 \%$ & $62.3 \%$ & $34.6 \%$ \\
Difficulty with change & $5.3 \%$ & $55.1 \%$ & $39.6 \%$ \\
Anger, temper tantrums, meltdowns & $5.7 \%$ & $48.4 \%$ & $45.8 \%$ \\
Anxious, agitated, nervous & $13.0 \%$ & $44.3 \%$ & $42.7 \%$ \\
Problems with play & $26.7 \%$ & $39.6 \%$ & $33.7 \%$ \\
Extreme fear and nervousness & $34.0 \%$ & $39.2 \%$ & $26.8 \%$ \\
Difficulty in relating to other children & $7.2 \%$ & $39.3 \%$ & $53.4 \%$ \\
Bedtime routine and sleeping & $25.7 \%$ & $38.2 \%$ & $36.1 \%$ \\
Unusual response to something new & $27.3 \%$ & $35.8 \%$ & $36.9 \%$ \\
Issues with school, homework & $26.8 \%$ & $32.1 \%$ & $41.1 \%$ \\
Eating & $39.6 \%$ & $29.2 \%$ & $31.3 \%$ \\
Unusual reaction to pleasant situations & $41.5 \%$ & $24.9 \%$ & $33.6 \%$ \\
Unusual interest in toys or objects & $57.6 \%$ & $13.8 \%$ & $28.6 \%$ \\
\hline
\end{tabular}

In the table the items are re-ordered from high to lowest percentage on 'getting better' ratings

referral options, mostly group-based training or the RAFT project. However no records were available about the number of families who declined a referral to the RAFT project at this stage but a Trust informant thought it was low.

Table 2 Mean (and Standard Deviations) of parental ratings (out of 10) prior to and after the intervention $(N=$ 427)

\begin{tabular}{lll}
\hline Items & Mean prior & Mean after \\
\hline Feeling stressed/relaxed & 4.78 & 6.23 \\
& $(2.16)$ & $(2.13)$ \\
I spend most of my time in the house/out and about & 5.80 & 6.71 \\
Feeling Down/great & $(3.04)$ & $(2.91)$ \\
& 6.02 & 7.09 \\
I have no difficulty managing my child & $(2.06)$ & $(1.95)$ \\
& 6.26 & 7.42 \\
Lonely/have friends & $(2.38)$ & $(2.04)$ \\
I find it hard to manage/can manage the day-to-day tasks of running a home & 6.52 & 7.14 \\
Overall, my health is poor/ good & $(3.10)$ & $(2.86)$ \\
& 6.94 & 7.82 \\
Overall quality of life poor/good & $(2.47)$ & $(2.15)$ \\
& 6.96 & 7.59 \\
\end{tabular}


On referral to the RAFT project, personal contact is made with the families. At this point some families declined the service or it became apparent that the service was not suited to the needs of the child and/or the family. Also some families commenced the service but later dropped out. Some parents explicitly give a reason - the birth of another child for example - but others were discharged due to a failure to keep appointments.

Over the four years when the project was fully operational, 456 children participated in it: $85 \%$ of the 534 children who had been referred to it. In all, 48 parents $(9 \%)$ declined the offer of a place, $26(5 \%)$ dropped out with only three $(0.6 \%)$ inappropriate referrals on account of age. Among the 456 participating children, there were 56 siblings in 29 families. Thus 427 families had participated.

The project staff reported a median of five home visits per family who completed the project (range 1 to 12 ). The sessions took place over a median period of eight weeks ranging from 1 to 51 weeks (the latter because of postponements of visits due to mother's health or the arrival of a new baby). In all, 2215 visits were made to families who completed the project over the four years.

The child was present for a median of one session (range 0 to 9 sessions). Overall for $38 \%$ of family visits, the child was never present but for $18 \%$ the child was always present. For children under 4 years of age, the child was present for a median of $90 \%$ of the visits but for children aged 9 and over, the comparable percentage was $15 \%$. As the home visit took place in school hours, these figures are to be expected.

In all, $87 \%$ of families had no missed appointments but a total of 77 missed appointments were recorded for 60 families over the four years. This represents around $3 \%$ of all visits. However $43 \%$ of families had cancelled an arranged appointment (which was then re-arranged); a total of 199 cancellations was recorded over the four years (9\% of recorded appointments).

\section{Characteristics of the Children}

Of the 456 children participating in the project, 331 were boys (72.6\%) and 125 $(27.4 \%)$ were girls. Their mean age was 7.0 years (range 2.6 to 13.6). In all, 393 $(86 \%)$ had received a diagnosis of ASD; 54 (12\%) were waitlisted for assessment but seven $(2 \%)$ children had no diagnosis of ASD and were listed for review.

The mean age at which children had received a diagnosis was 5.7 years (range 1.5 to 12 years). Overall 37\% had been diagnosed when under five years of age; $49 \%$ between five and seven years, and $15 \%$ when they were eight years and over.

In all, $17 \%$ of children on the project were reported to have received their diagnosis within the past six months and a further $31 \%$ between 6 and 12 months; whereas $33 \%$ had been diagnosed between one and two years previously and $19 \%$ more than two years (range 2 to 14 years). In 2019, there were significantly lower proportions of children diagnosed up to 6 months previously (9\%) compared to previous years (20\%). This suggests that recently these families had to wait longer to commence the RAFT project due to increasing numbers of children being diagnosed.

Of the 456 children in the project, $25 \%$ were reported to have additional problems as well as ASD. In all $13 \%$ had a learning disability and $10 \%$ had a medical problem and $2 \%$ had vision or hearing impairment. ADHD was frequently noted as an additional difficulty. 
Two-thirds of children attended mainstream schools (68\%) with $14 \%$ attending a nursery school or a preschool. In all $9 \%$ attended a special school and $1 \%$ a unit attached to a mainstream a school (10\% combined). Overall $9 \%$ of children did not attend any educational facility; mostly those under four years of age.

Around one third of children $33 \%$ were currently seeing a health professional. Of these $24 \%$ were receiving speech and language therapy and $11 \%$ were seeing an occupational therapist. A small number $(6 \%)$ were receiving behavioural support (such as the RISE programme in school) and $2 \%$ mentioned ongoing contact with a social worker. Various other therapies were mentioned such as music and art therapy for a few children. However additional families had previously seen a therapist or were waiting to do so.

A small number of families (9\%) currently used some form of specific autism interventions such as PECS or other visual systems and eight (2\%) used ABA (positive reinforcement).

\section{Family Characteristics}

In the 427 participating families, the child with ASD was the only child in $5 \%$ of families and the first born in a further $45 \%$ of families. They were the second or subsequent born in $50 \%$ of families.

In most families, mothers were named as the primary carer (91\%) although this percentage also includes families who indicated that both parents were carers. However fathers were the main carer in $8 \%$ of families and another relative (such as grandparent) in $1 \%$ of families.

In all, $50 \%$ were married couples and $18 \%$ were living with partners; $26 \%$ were single parents and $7 \%$ were separated, divorced or widowed. The percentage of lone parents $(33 \%)$ is higher than the Northern Ireland average of $25 \%$ with dependent children (Office of National Statistics 2020a).

The majority of carers were aged 30-39 years (54\%) with $17 \%$ aged under 30 years; $24 \%$ aged $40-49$ and $5 \%$ aged 50 to 59 years.

In all, $41 \%$ of the primary carers had attended higher education with $39 \%$ completing secondary education but $20 \%$ left school at 16 years without any qualifications.

In $69 \%$ of families there was a wage earner but not for $31 \%$ of families who were presumably dependent on social security benefits. In all, $50 \%$ were renting their homes, $47 \%$ were owner-occupiers with $3 \%$ living with relatives or in other forms of accommodation, such as hostels. The proportion in rented accommodation is much higher than the Northern Ireland average of 21\% (Office of National Statistics 2020b).

Nearly all the parents were white Irish/British (99\%) with $1 \%$ from Asian or Caribbean ethnicities.

Almost half the parents (46\%) reported that another family member had a disability of which $39 \%$ had ASD. Siblings, cousins, parents and uncles were identified.

\section{Social Deprivation and Disadvantage}

The proportion of families living in areas of social deprivation was ascertained using the Multiple Deprivation Measures for Northern Ireland (NISRA 2017). The latter ranks districts in terms of the centiles of deprivations. In all $20 \%$ of families resided in 
the top $20 \%$ of areas in Northern Ireland with the highest levels of social deprivation whereas $34 \%$ lived in the $20 \%$ of areas that were least deprived. By comparison, for the HSC trust as a whole, $13 \%$ lived in the most deprived areas and $18 \%$ in the least deprived areas.

However a higher percentage of the 30 families who declined to participate or who dropped out of the project lived in the most deprived areas (43\%) compared to $20 \%$ in the least deprived areas who participated in the project (Chi Sq 5.64: $p<0.05$ ).

Disadvantage was also examined in terms of three indicators used in past research [17]: namely living in rented accommodation, left school at 16 years and no wage earner in the household. In all, 7\% of participating families met all three criteria and a further $36 \%$ met one of the three criteria. In total, this represents $43 \%$ of participants with $57 \%$ of families not meeting any of these indicators.

Although the project has succeeded in its intention to reach more socially disadvantaged families, a higher proportion of the families who declined to participate in the project tended to have one or more of these vulnerabilities $(61 \%)$ compared to those with none $(39 \%)$ (Chi Sq $3.61 p<0.06)$.

\section{Results}

\section{Participation by Families}

Staff rated the parent's cooperation with the project on a four-point rating scale as follows: 217 families (55\%) were rated as very good; 99 (22\%) as good; $82(18 \%)$ as adequate) and $17(4 \%)$ as poor. (Note: this information was not available for 12 families).

These ratings were significantly related to certain parental characteristics. With those who lived in the more deprived areas, their cooperation tended to be rated adequate or poor compared to those living in the least deprived areas (32\% v 18\%: Chi Sq 15.74 $p<0.05)$. Likewise those who were single parents, or who had left school at 16 years and or when there was no wage earner in the family tended to be rated as adequate or poor cooperation (31\% v 15\%: Chi Sq $21.64 p<0.001$ ). However none of the child characteristics were significantly related to these ratings of cooperation.

Overall $25 \%$ of parents reported they had attended one or more training courses provided by the project and a further two parents indicated that they had previously done so, but $75 \%$ had not attended any training. Single parents or those who left school at 16 or those with no wage earner in the family were significantly less likely to have attended training (17\% attended compared to $31 \%$ of those with none of these vulnerabilities: Chi Sq $11.49 p<0.05)$.

Although project staff had signposted $83 \%$ of parents to local Autism NI supports, they reported that only $11 \%$ had attended any.

\section{Parental Reactions to the Project}

Parents rated their satisfaction with the project using a three-point scale. Overall $96 \%$ were very satisfied and $4 \%$ were satisfied with the help they had received. No one chose the dissatisfied option. (12 parents did not respond.) Similarly, 368 parents (83\%) 
felt the number of sessions were 'just right' with 73 (13\%) indicating they were too short with one parent choosing the 'too long' option (12 parents did not respond). Families who had received six or more sessions were more likely to consider them as too short (30\%) compared to those who had received five or fewer sessions (10\%) (Chi Sq 28.96: $p<0.001)$ which may be indicative of a need for more sustained interventions.

The interventions they felt had been of most benefit to them were visual strategies (90\% parents mentioned), information that was provided (45\%), having a 'listening ear' $(33 \%)$ and structuring the environment $(19 \%)$.

In all, $92 \%$ of parents felt their child had benefited from the interventions provided but $8 \%$ felt it was too soon to tell and one chose 'no benefit (16 parents did not respond). When asked if the child's quality of life had improved; $66 \%$ felt it had; $19 \%$ felt it had 'somewhat' improved; $14 \%$ thought it was 'too soon to tell' and $1 \%$ chose 'no' improvement.

Parents were asked to indicate the positive outcomes from the project for their child and family. The most commonly mentioned topics were: use of visuals, charts, schedules, fewer tantrums and meltdowns, child was less anxious and was more independent and doing things for self. When asked about 'unexpected outcomes' the most commonly mentioned was referral to other agencies, particularly on school and educational issues; having a listening ear and the provision of resources. Parents made few suggestions as to how the project could be improved.

In 2019, 69 parents received a follow-up phone call from project staff. This call took place on average 12 weeks after the final home visit (range 3 to 24 weeks). When asked if the parents felt they would benefit from further visits in the immediate future, $17 \%$ responded yes. Some of those declining noted that maybe in the future more visits would be helpful, for example if the child was moving school or they felt able to contact the project if the need arose. However this figure accords with that noted earlier of $13 \%$ parents who had felt the number of visits was too short.

\section{Changes in Parents' Perceptions of children's Difficulties}

Parents were asked to rate the changes there had been in their child since their involvement with the project based on commonly occurring problems experienced by children with ASD (see Table 1).

Three options were provided. The first column indicates the issues that were of concern to families about their child with ASD at the start of their involvement with the project: the lower the percentage, the more children for whom the difficulty was identified. All but one of the 14 listed difficulties were ones affecting the majority of families. Surprisingly this one was an unusual interest in toys or objects which is considered one of the defining features of autism.

Column two presents the parental ratings of problems that were getting better since the project commenced. The three most frequently mentioned changes by the majority of parents were improvements in personal care, problems in following instructions and difficulty with change. Nearly half mentioned the child was less angry and had fewer tantrums or meltdowns. In all, parents reported a median of four problems that were getting better (range 1 to 14 ). 
The third column indicates the difficulties that remained a problem even though project staff had tried to addressed them and as such they represent a continuing need for children and families. The most common were difficulties in relating to other children, anger and meltdowns, anxiety and issues with schooling. All parents reported having ongoing problems with a median of four issues as a continuing problem (range 1 to 13). Those families which had received six or more visits reported a higher number of ongoing problems (mean 5.1) compared those who had five or less sessions (mean 4.3) $(\mathrm{F}=4.23: p<0.05)$. This suggests that some families may need some further ongoing support although only a minority seemed to want it currently.

\section{Changes in Parental Well-Being}

Mothers were asked to rate out of 10 their well-being on an eight item scale that had been devised for the project. For each item, the two ends of the scale were named: for example "overall my health is poor" - score 1 - and "my health is good" - score 10. A higher score indicated ratings towards the positive side.

Table 2 summarises the mean score given by mothers for each item (out of 10) at the start and after the intervention. All showed significantly increased scores at the end of the project (Paired T-Tests $p<0.001$ ).

When a summary score was calculated for these eight items (minimum score 8: maximum score 80 ), this too showed a significant improvement after the project. (Before the mean score $=51.0$ and after mean $=57.8: \mathrm{t}=18.31: p<0.001$ ). (Higher scores are indicative of better wellbeing). Hence the project led to improvements in parental well-being: notably less stress, not feeling so down, less lonely and managing their child better. Overall, five parents $(2 \%)$ had lower wellbeing scores or same scores at the end of the project whereas others had a median improvement of 12 points (range 1 to 33$)$.

However parents who had higher wellbeing scores after the project were those whom staff had rated as having good cooperation with the service (Mean $59.6 \mathrm{v}$ 54.8: $\mathrm{F}=4.66: p<0.001)$. Also single parents or those who left school at 16 or where there was no wage-earner in the family, had significantly lower wellbeing scores than parents with none of these characteristics at the end of their time on the project (mean 55.7 v 60.9: $f=16.33: \mathrm{p}<0.001$ ) although the scores of the two groupings were also significantly different at the start of their involvement (mean $48.7 \mathrm{v} 52.8$ : $\mathrm{f}=6.15$ : $p<0.05)$.

Parents also reported a significant increase in the rating they gave to three further items: family getting on well together (mean before: 7.64: after 8.09); knowing where to get help (mean before 6.88: after 8.81 and taking part in the local community (mean before 3.84: after 4.34). However the latter figure indicates that over $50 \%$ of parents still have little involvement in their local community.

\section{Staff Perceptions of the Project}

Interviews and self-completed questionnaires were completed with project staff and the leader of the Children's ASD team who had referred children to the project $(n=5)$. They identified the following features as being crucial to the success of the project: 
home visits by a specialist in autism over multiple weeks; personalized and individualized ASD approaches; empowerment of parents and opportunities for peer support.

The average cost per family of their participation in the project was estimated at $£ 1000$.

Among the improvements staff noted: more availability of late afternoon or evening appointments for families to provide opportunities to work with the children; extending the number of sessions up to eight; liaising with schools about the implementation of similar strategies there to those used at home and more social opportunities for parents and for children.

The project funding was time limited but staff were eager to see the project continue. The leader of Trust team referring children commented:

\section{"It has been an invaluable resource to the Trust in the support package and care plan available to children with ASD. I feel that support delivered in local communities help develop resilience skills and coping mechanisms for families through the network of local support that the community develops, helping children and their families to thrive."}

However the project was discontinued when the charitable funding ended and the Trust did not have the resources to sustain it.

\section{Discussion}

The brief intervention and its evaluation was unique in a number of respects. Since its inception, over 500 children from 470 families drawn from targeted geographical areas were involved over a five-year period. The families came from a range of backgrounds including those who were socially disadvantaged. The take-up rate for the project was high: $87 \%$ of all referrals and the drop-out rate was low (4.5\%) as was the proportion of missed and cancelled appointments. The children mostly attended mainstream schools but the families reported often having no access to advice and guidance to cope with the issues the child with ASD presented at home. Indeed only a small minority of families were receiving therapy and hardly any were using specialist programmes to address autism.

The project had emphasised the use of visual strategies and positive routines with a focus on empowering parents to make changes and sign-posting them to other support services. Most parents felt their child had benefited from the advice given; as had they and other family members. In addition, parental wellbeing seems to have been boosted by the project. The emotional support provided by project staff (their 'listening ear') may account for this as previous research has suggested (Bonis 2016). The family as a whole also benefited from a calmer home environment when children's meltdowns and challenging behaviours were reduced (Nagib and Williams 2018).

The project seems to be very cost-effective with estimated costs per family of around $£ 1000$. This compares to an estimated average cost of $£ 850$ of assessing and diagnosing a child with ASD in the UK (Galliver et al. 2017). However further research is warranted on this issue as noted below. 


\section{Post-Diagnostic Support for Families}

The project has identified a number of issues relating to post-diagnostic support for children with ASD and their families, at least in this region of the UK but they may also apply elsewhere.

Only $17 \%$ of the children who participated in the project had received their diagnosis up to six months previously with a further $31 \%$ up to 12 months. More than half the children had waited over 12 months for personalised, post-diagnostic support. Yet international opinion favours speedy referral for intervention (NICE 2016). The delay is compounded by the increased numbers of children being diagnosed which results in longer waiting times for access to post-diagnostic support. One solution is to increase the resources available for the provision of post-diagnostic support yet health and social care funds seems to be targeted mainly at assessment services which in this instance, resulted in the termination of the project despite the evidence of its impact on families.

More families could have been accommodated in the project by having a fewer number of home visits per family. However the number of visits each family received varied from two to 12 with most parents reporting that the number of sessions they received was 'just right', irrespective of the number of visits they received. This would suggest that staff negotiated with parents, their need for further visits and the time period covering them but even then, there may be scope for an overall reduction in home visits allied with some form of continuing contact such as telephone reviews and group meetings. Nevertheless the risk is that briefer and less personalised interventions will be less effective.

Moreover, the alternative option of providing group-based training to parents rather than home visits may not be effective (O’Donovan et al. 2019). There was a low uptake of training courses by parents on the project despite the apparent wish of parents to attend further training. However parents commented that courses often do not meet their individual needs. Moreover, the location of the training and its timing could be factors that impede parental attendance alongside issues of childcare and taking time off from work, especially for low resourced families.

The challenges of engaging disadvantaged families in health and social services are well documented and this is evident too from the experiences of the RAFT project. Although a higher proportion of these families took part than those identified in the Trust area as a whole, a higher proportion of these families declined the service when it was offered to them. The engagement of these families with the project was more likely to be rated as adequate or poor and lower proportions attended training courses. The parents also had lower wellbeing scores. Perhaps with these parents, greater attention needs to be paid to the broader needs of the families rather than focussing on the needs of the child with ASD which could be a lesser concern to the parents They may also benefit from more sustained contact over a longer period of time and from a more integrated support package that covered other issues, such as employment and housing (Karp et al. 2018).

Although all the children in the project attended school, there was little or no contact between the project and schools which mirrored a seeming lack of contact which parents have with teachers. Yet school issues remained one of the continuing difficulties that parents reported. It is also puzzling that the parents had not been advised or assisted by schools to use the visual prompts and charts that the parents felt had been very helpful to their child. Improved communication between parents and teachers is needed (Azad and Mandell 2016). The advantages of integrated working between 
health, social care and education have been noted in the literature and were reiterated by project staff; particularly in giving the children consistency in the strategies used to overcome their difficulties (Hurt et al. 2019). Future intervention projects should attempt to address the issue of home-school links more proactively.

Further studies could usefully undertake a closer investigation of the cost-benefits of home-based interventions (Vivanti et al. 2018). Moreover sparse details are available in the literature of the costs of service provision and still less, linking the costs to the outcomes achieved (Knapp and Buescher 2014). The balance between the spending on assessment and diagnostic services and the provision of post-diagnostic support merits particular attention; especially as the latter may result in a reduction in costs to families of having a child with ASD (Horlin et al. 2014).

\section{Limitations}

The evaluation of the project had a number of limitations which future projects might address.

The project did not undertake a longer-term, follow-up of families to determine if the changes reported have been maintained and maybe extended in later years. This would require additional evaluation resources which were not covered by the project funding; a common occurrence in service funding.

The impact on the children of the interventions has not been directly assessed in this evaluation although parental reports are favourable. Future studies might attempt to measure children's behaviours at home and changes over the time of the project, for example by project staff using a standard rating scale.

The child's perceptions of the project were not sought largely because the staff had limited contact with the children and their young age would present extra challenges. Nevertheless their insights could help shape the advice given to parents and guide family-based interventions (Zuber and Webber 2019).

Acknowledgements The project was funded by the UK Big Lottery.

\section{Compliance with Ethical Standards}

Conflict of Interest AM was the manager of the project and KB provided overall oversight of it. RM was commissioned by AutismNI to undertake an independent evaluation of it for which he received a fee.

Ethical Approval All procedures performed in the study involving human participants were in accordance with the ethical standards of the institutional committee and with the 1964 Helsinki declaration and its later amendments or comparable ethical standards.

Informed Consent Informed consent was obtained from parents for the project to obtain and retain information in line with EU Data Protection Procedures. Assurances of confidentiality were given and parents were told that they can refuse to provide any or all information without it affecting their participation in the service.

Open Access This article is licensed under a Creative Commons Attribution 4.0 International License, which permits use, sharing, adaptation, distribution and reproduction in any medium or format, as long as you give appropriate credit to the original author(s) and the source, provide a link to the Creative Commons licence, and indicate if changes were made. The images or other third party material in this article are included in the 
article's Creative Commons licence, unless indicated otherwise in a credit line to the material. If material is not included in the article's Creative Commons licence and your intended use is not permitted by statutory regulation or exceeds the permitted use, you will need to obtain permission directly from the copyright holder. To view a copy of this licence, visit http://creativecommons.org/licenses/by/4.0/.

\section{References}

Allison, C., Auyeung, B., \& Baron-Cohen, S. (2012). Toward brief "red flags" for autism screening: The short autism spectrum quotient and the short quantitative checklist in 1,000 cases and 3,000 controls. Journal of the American Academy of Child and Adolescent Psychiatry, 51(2), 202-212.

Althoff, C. E., Dammann, C. P., Hope, S. J., \& Ausderau, K. K. (2019). Parent-mediated interventions for children with autism Spectrum disorder: A systematic review. American Journal of Occupational Therapy, 73(3), 7303205010p1-7303205010p13. https://doi.org/10.5014/ajot.2019.030015.

Azad, G., \& Mandell, D. S. (2016). Concerns of parents and teachers of children with autism in elementary school. Autism, 20(4), 435-441.

Bonis, S. (2016). Stress and parents of children with autism: A review of literature. Issues in Mental Health Nursing, 37(3), 153-163.

Carr, T., \& Lord, C. (2016). A pilot study promoting participation of families with limited resources in early autism intervention. Research in Autism Spectrum Disorders, 25, 87-96.

Crane, L., Chester, J. W., Goddard, L., et al. (2016). Experiences of autism diagnosis: A survey of over 1000 parents in the United Kingdom. Autism, 20(2), 153-162.

Department of Health. (2018). The autism strategy (2013-2020): Draft second Progress report. Belfast: Department of Health.

Elsabbagh, M., Divan, G., Koh, Y. J., Kim, Y. S., Kauchali, S., Marcín, C., Montiel-Nava, C., Patel, V., Paula, C. S., Wang, C., Yasamy, M. T., \& Fombonne, E. (2012). Global prevalence of autism and other pervasive developmental disorders. Autism Research, 5(3), 160-179.

Galliver, M., Gowling, E., Farr, W. et al. (2017). Cost of assessing a child for possible autism spectrum disorder? An observational study of current practice in child development centres in the UK. BMJ Paediatrics Open 1(1),

Haine-Schlagel, R., \& Walsh, N. E. (2015). A review of parent participation engagement in child and family mental health treatment. Clinical Child and Family Psychology Review, 18, 133-150.

Hood, R., Goldacre, A., Gorin, S., et al. (2019). Screen, ration and churn: Demand management and the crisis in children's social care. British Journal of Social Work, 50(3), 868-889.

Horlin, C., Falkmer, M., Parsons, R., Albrecht, M. A., \& Falkmer, T. (2014). The cost of autism spectrum disorders. PLoS One, 9(9), e106552.

Hurt, L., Langley, K., North, K., Southern, A., Copeland, L., Gillard, J., \& Williams, S. (2019). Understanding and improving the care pathway for children with autism. International Journal of Health Care Quality Assurance, 32(1), 208-223.

Karp, E. A., Dudovitz, R., Nelson, B. B., et al. (2018). Family characteristics and children's receipt of autism services in low-resourced families. Pediatrics, 141(supplement 4), S280-S286.

Karst, J. S., \& van Hecke, A. V. (2012). Parent and family impact of autism spectrum disorders: A review and proposed model for intervention evaluation. Clinical Child and Family Psychology Review, 15(3), 247277.

Kasari, C., Lawton, K., Shih, W., et al. (2014). Caregiver-mediated intervention for low-resourced preschoolers with autism: An RCT. Pediatrics, 134(1), 72-79.

Knapp, M., \& Buescher, A. (2014). Economic aspects of autism. In F. R. Volkmar et al. (Eds.), Handbook of autism and pervasive developmental disorders (Fourth ed., pp. 1089-1106). London: Wiley.

Kogan, M.D., Vladutiu, C.J., Schieve, L.A. et al. (2018). The prevalence of parent-reported autism spectrum disorder among US children. Pediatrics,142(6), e20174161.

Landa, R. J. (2018). Efficacy of early interventions for infants and young children with, and at risk for, autism spectrum disorders. International Review of Psychiatry, 30(1), 25-39.

McConkey, R. (2020a). The rise in the numbers of school pupils with autism: A comparison of the four countries in the United Kingdom. Support for Learning, 35(2), 132-143.

McConkey, R. (2020b) A brief measure of parental wellbeing for use in evaluations of family-centered interventions for children with developmental disabilities. Children, 7, 120.

McConkey, R., MacLeod, S., \& Cassidy, A. (2011). The keyhole® rainbow resource kit: Meeting the needs of parents of newly diagnosed preschoolers with ASD. Early Child Development and Care, 181(3), 321334. 
Manohar, H., Kandasamy, P., Chandrasekaran, V., \& Rajkumar, R. P. (2019). Brief parent-mediated intervention for children with autism Spectrum disorder: A feasibility study from South India. Journal of Autism and Developmental Disorders, 49(8), 3146-3158.

Nagib, W., \& Williams, A. (2018). Creating "therapeutic landscapes" at home: The experiences of families of children with autism. Health \& Place, 52, 46-54.

NICE Clinical Guidance CG142 (2016). Available at: www.nice.org.uk/CG142.

NISRA. (2017). Northern Ireland Multiple Deprivation Measures 2017. Available at: https:/www.nisra.gov. uk /statistics/deprivation /northern-ireland-multiple- deprivation-measure-2017-nimdm2017

O’Donovan, K. L., Armitage, S., Featherstone, J., et al. (2019). Group-Based Parent Training Interventions for Parents of Children with Autism Spectrum Disorders: a Literature Review. Review Journal of Autism and Developmental Disorders, 6(1), 85-95.

Office of National Statistics. (2020a). Families by family type, regions of England and UK constituent countries. Available at: https://www.ons.gov.uk/peoplepopulationandcommunity /birthsdeathsandmarriages /families/datasets /familiesbyfamilytyperegionsofenglandandukconstituentcountries

Office of National Statistics. (2020b). UK private rented sector: 2018. Available at: https://www.ons.gov. uk/economy/inflationandpriceindices /articles/ukprivaterentedsector/2018\#toc

Peacock, S., Konrad, S., Watson, E., et al. (2013). Effectiveness of home visiting programs on child outcomes: a systematic review. BMC Public Health, 13(1), Article 17.

Tellegen, C. L., \& Sanders, M. R. (2014). A randomized controlled trial evaluating a brief parenting program with children with autism spectrum disorders. Journal of Consulting and Clinical Psychology, 82(6), 193-1200.

Vasilopoulou, E., \& Nisbet, J. (2016). The quality of life of parents of children with autism spectrum disorder: A systematic review. Research in Autism Spectrum Disorders, 23, 36-49.

Vivanti, G., Kasari, C., Green, J., Mandell, D., Maye, M., \& Hudry, K. (2018). Implementing and evaluating early intervention for children with autism: Where are the gaps and what should we do? Autism Research, 11(1), 16-23.

Zand, D. H., Bultas, M. W., McMillin, S. E., et al. (2018). A pilot of a brief positive parenting program on children newly diagnosed with autism spectrum disorder. Family Process, 57(4), 901-914.

Zuber, W. J., \& Webber, C. (2019). Self-advocacy and self-determination of autistic students: A review of the literature. Advances in Autism, 5(2), 107-116.

Publisher's Note Springer Nature remains neutral with regard to jurisdictional claims in published maps and institutional affiliations. 